\title{
RENDIMENTO E CARACTERÍSTICAS FÍSICO-QUÍMICAS DO EXTRATO DA CASCA DO JAMBO PROCESSADO EM SPRAY DRYER - INFLUÊNCIA DAS VARIÁVEIS DE OPERAÇÃO.
}

\author{
E. C. LIMA ${ }^{1}$, M. E. RODRIGUES ${ }^{1}$, J. L. MAIA ${ }^{1}$, T. N. P. DANTAS ${ }^{1}$, M. F. D. \\ MEDEIROS $^{1}$. \\ ${ }^{1}$ Universidade Federal do Rio Grande o Norte, Departamento de Engenharia Química \\ E-mail para contato: cortezerica.97@gmail.com
}

\begin{abstract}
RESUMO - O jambo vermelho possui propriedades benéficas à saúde humana, uma delas ainda pouco explorada, as antocianinas presentes na casca da fruta. Este composto bioativo tem ação antioxidante, além de ser uma alternativa natural para obtenção do corante vermelho utilizado nas indústias de alimentos e cosméticos. Entretanto, as antocianinas são vulneráveis à parâmetros ambientais, fazendo-se necessário o seu processamento. Os secadores por nebulização conhecidos como Spray Dryers maximizam a área de troca de calor e massa durante a secagem e devido ao pequeno tempo de residência do produto na câmara de secagem, tornouse o principal equipamento para secagem de materiais sensíveis ao calor, como leveduras, enzimas, proteínas e corantes. Assim, realizou-se a secagem do extrato da casca do jambo utilizando goma arábica como adjuvante por este método. Foram efetuados a caracterização físico-química dos pós e o cálculo do rendimento, analisando-se estatisticamente os efeitos da temperatura e concentração do adjuvante sobre o rendimento, umidade, atividade de água, solubilidade e higroscopicidade dos pós. Apenas o rendimento sofreu efeitos significativos da temperatura e da interação temperatura X concentração, negativo e positivo, respectivamente.
\end{abstract}

\section{INTRODUÇÃO}

Amplamente encontrado nas regiões Norte e Nordeste, o jambo vermelho é uma fruta tropical rica em antocianinas, composto bioativo responsável pela coloração vermelha característica de muitas espécies frutíferas. Além de ser um pigmento natural, muitos estudos têm relacionado as antocianinas a uma significativa propriedade antioxidante que ocorre por diversos mecanismos e que tem um grande impacto na prevenção de doenças neuronais e cardiovasculares, diabetes (KONCZAK, ZHANG, 2004) e no tratamento de outras como o câncer (LULE, XIA, 2005).

No entanto, esta propriedade é bastante sensível aos fatores ambientais, degradando-se facilmente. Uma forma promissora de prolongar a vida útil deste composto é a microencapsulação por spray dryer, pois melhora a estabilidade dos corantes naturais que são facilmente degradados por fatores como luz, oxigênio e temperatura (BOBBIO et al., 2000). Neste processo, a partícula de interesse é revestida por uma membrana polimérica (adjuvante) 
formando microcápsulas as quais podem liberar seu conteúdo de forma controlada e sob condições específicas. Esta técnica pode reduzir a volatilidade e reatividade do material, aumentando sua estabilidade em condições ambientais adversas.

\section{OBJETIVOS}

Caracterizar as propriedades físico-químicas dos produtos obtidos a partir da secagem em spray dryer do extrato da casca do jambo com adição de goma arábica e analisar o efeito das condições de temperatura e concentração de goma sobre o rendimento da produção, umidade, atividade de água, higroscopicidade e solubilidade dos pós.

\section{METODOLOGIA}

\subsection{Obtenção do extrato da casca do jambo}

A princípio, os jambos semelhantes aos da Figura 1 foram coletados, selecionados, lavados em água corrente para retirada do excesso de impurezas, higienizados com água clorada por 10 minutos, lavados com água destilada e enfim despolpados com auxílio de uma faca inox. As cascas foram submersas em água destilada na proporção de 1:3 (peso/volume), trituradas, peneiradas, separadas em porções de $300 \mathrm{~g}$ e congeladas à uma temperatura de $-18^{\circ} \mathrm{C}$. Variou-se o percentual de goma arábica adicionado à solução e a temperatura de secagem conforme um delineamento experimental $2^{2}$ com 3 réplicas na condição intermediária de temperatura e concentração de goma.

Figura 1 - Jambos coletados

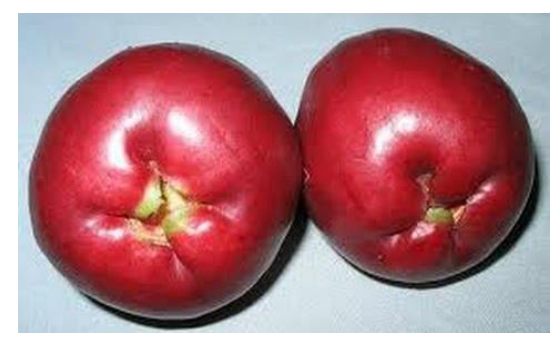

\subsection{Secagem em Spray Dryer}

Utilizou-se na secagem um spray dryer modelo MSD 1.0 fabricante LABMAQ DO BRASIL LMTD sob as seguintes condições operacionais: vazão da solução (L/h) 0,67; vazão da bomba $\left(\mathrm{m}^{3} / \mathrm{min}\right), 1,65$; e rotâmetro (L/min) 0,35 . Uma solução previamente preparada conforme a da Figura 2 é descongelada e é adicionado um percentual de goma arábica à mistura, a qual permanece sob agitação durante todo o procedimento. A solução é bombeada e por meio de uma mangueira de silicone chega até ao bico atomizador onde o líquido é pulverizado e, instantaneamente, uma corrente de ar quente em paralelo seca as micropartículas. Os sólidos de maior tamanho ficam retidos no fundo da câmara de secagem, as partículas muito pequenas são expelidas por um tubo na parte superior do ciclone e as partículas de tamanho desejado são coletadas no recipiente de vidro na saída inferior do 
ciclone. Ao término do processo, o pó similar ao mostrado na Figura 3 é pesado e armazenado sob refrigeração até o momento de ser caracterizado.

Figura 2 e 3 - Solução do extrato da casca do jambo e o pó obtido na secagem, respectivamente
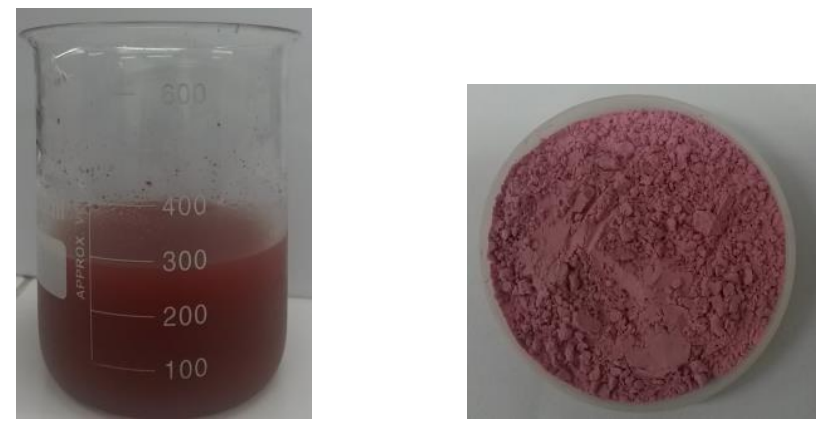

\subsection{Análises físico-químicas}

Higroscopicidade: Inicialmente, pesou-se $40 \mathrm{~g}$ de cloreto de sódio, adicionou em $100 \mathrm{~mL}$ de água destilada, agitou-se e, por fim, a solução foi colocada no fundo de um dessecador dentro de uma placa de petri. Colocou-se $0,5 \mathrm{~g}$ de pó em pesa-filtros os quais foram postos junto com a solução aquosa de $\mathrm{NaCl}$ dentro do dessecador e deixados por uma semana à temperatura de $25^{\circ} \mathrm{C}$. Determinou-se a higroscopicidade por diferença de massas.

Solubilidade: Utilizou-se o método de Eastman \& Moore (1984) modificado por Cano-Chauca et al., (2005). Nesta análise, preparou-se uma mistura de 1,0g de pó em 100mL de água destilada e a centrifugou por 5 minutos a $2600 \mathrm{rpm}$. Um volume de $20 \mathrm{~mL}$ de sobrenadante foi retirado e adicionado em pesa-filtros para então ser colocado em uma estufa à $70^{\circ} \mathrm{C}$ até atingir massa constante. Calculou-se a solubilidade pela diferença de massas.

Atividade de água: Colocou-se uma pequena quantidade de pó em um recipiente e a análise foi realizada por um medidor de atividade de água do tipo AQUALAB.

Umidade: Adicionou-se 1,0g de pó em uma balança de umidade por infravermelho durante 3 h até o aparelho fornecer o percentual de umidade.

\subsection{Rendimento}

A partir dos valores de massa da solução de alimentação no secador, massa do pó obtido, umidade da solução e umidade do pó, determinou-se o rendimento aplicando a Equação 1.

$R(\%)=\frac{m_{p o} \times\left(1-u_{p o}\right)}{m_{\text {alimentada }} \times\left(1-u_{\text {alimentada }}\right)} \times 100$ 


\section{RESULTADOS}

A matriz experimental com os resultados de todos os experimentos, realizados de acordo com o delineamento experimental $2^{2}$ com 3 réplicas no ponto central são exibidos na Tabela 1.

Tabela 1 - Planejamento Fatorial $2^{2}$ - Matriz das variáveis independentes e variáveis de resposta para todos os experimentos

\begin{tabular}{cccccccc}
\hline Ensaio & $\mathrm{T}\left({ }^{\circ} \mathrm{C}\right)$ & $\mathrm{C}(\%)$ & $\mathrm{u}_{\mathrm{pó}}(\%)$ & $\mathrm{H}(\%)$ & $\mathrm{S}(\%)$ & $\mathrm{aW}$ & $\mathrm{R}(\%)$ \\
\hline E1 & $150(+1)$ & $10(+)$ & 4,35 & 24,60 & 96,22 & 0,35 & 51,08 \\
E2 & $120(-1)$ & $10(+)$ & 5,57 & 23,67 & 98,79 & 0,36 & 51,94 \\
E3 & $150(+1)$ & $5(-)$ & 4,42 & 26,81 & 97,41 & 0,44 & 48,74 \\
E4 & $120(-1)$ & $5(-)$ & 3,6 & 24,16 & 98,07 & 0,39 & 58,74 \\
E5 & $135(0)$ & $7,5(0)$ & 4,19 & 25,64 & 96,2 & 0,35 & 47,32 \\
E6 & $135(0)$ & $7,5(0)$ & 4,08 & 25,40 & 94,07 & 0,37 & 48,2 \\
E7 & $135(0)$ & $7,5(0)$ & 4,9 & 25,69 & 94,45 & 0,39 & 46,34 \\
\hline
\end{tabular}

Conforme se observa na Tabela 1, a umidade do pó apresentou resultados bastante satisfatórios variando numa estreita faixa compreendida entre 3,6 e 5,57\%. Esta faixa de variação da umidade é compatível com as encontradas por Moreira et al.(2009) na secagem do extrato do bagaço de acerola em spray dryer utilizando maltodextrina como adjuvante, e confere ao produto em pó boas condições de conservação e armazenamento garantidas pela baixa atividade de água compreendida entre 0,35 e 0,44. A higroscopicidade mostrou-se elevada indicando que partículas com baixo teor de umidade possuem alta higroscopicidade devido à sua grande capacidade de absorver umidade do ambiente, o que está relacionado com o gradiente de pressão de vapor entre as partículas e o ar ambiente (BARBOSA, 2010). Valores de higroscopicidade próximos da faixa de 23,67 e 26,81\% também foram encontrados por Lancha et al. (2012) na atomização em spray de jabuticaba empregando maltodextrina como agente carreador. Os pós apresentaram solubilidade em água elevadas, superiores a 94\%, compatível com as encontradas por Tonon, Brabet e Hubinger (2013) na secagem em spray de açaí utilizando goma arábica como agente secante.

Com relação ao rendimento, o mesmo variou numa faixa compreendida entre 46,3 e $58,7 \%$. A elevada retenção nas paredes internas do secador é típica do processo de secagem em spray e pode vir a ser melhorada mediante ajuste da pressão do sistema de atomização de forma a minimizar a deposição da suspensão sobre as paredes do equipamento. Moura Neto (2011) obteve rendimentos de 44,40 a 49,90\% na secagem por atomização da polpa de cajá utilizando $3 \%$ de lecitina e $20 \%$ de maltodextrina como adjuvantes à $140^{\circ} \mathrm{C}$.

A análise estatística dos resultados foi realizada com a finalidade de se observar os efeitos das variáveis independentes, temperatura e concentração de goma sobre as variáveis respostas, umidade, atividade de água, solubilidade, higroscopicidade e rendimento. Foi utilizado o programa STATISTICS, versão 7.0 e técnicas estatísticas tendo como base a análise de variância para um grau de confiança de $95 \%$. Na tabela 2 é apresentado um resumo dos efeitos das variáveis independentes e da interação entre elas sobre as variáveis de 
resposta, onde os termos em destaque correspondem às variáveis independentes ou interação cujos efeitos apresentaram significância estatística.

Tabela 2 - Estimativa dos Efeitos para X, aW, S, H e R

\begin{tabular}{cccccc}
\hline & \multicolumn{5}{c}{ Efeitos Estimados } \\
\hline Variáveis Independentes & $\mathrm{X}(\%)$ & $\mathrm{aW}$ & $\mathrm{S}(\%)$ & $\mathrm{H}(\%)$ & $\mathrm{R}(\%)$ \\
Média & 4,44 & 0,38 & 96,4 & 23,71 & 50,34 \\
Temperatura & $-0,2$ & 0,02 & $-1,62$ & $-1,13$ & $\mathbf{- 5 , 4 3}$ \\
Concentração & 0,95 & $-0,06$ & 0,24 & $-5,03$ & $-2,23$ \\
TxC & 1,02 & $\mathbf{- 0 , 0 3}$ & 0,96 & $-4,51$ & $\mathbf{4 , 5 5}$ \\
\hline
\end{tabular}

De acordo com os dados apresentados na Tabela 2, verifica-se que o efeito da temperatura é o mais importante e interfere negativamente no rendimento, ou seja, na produção de pó. Também se verifica que em menor intensidade, o efeito combinado da temperatura e concentração é positivo, isto é, a ação combinada de maior temperatura e maior concentração ou menor temperatura e menor concentração aumenta o rendimento da produção. Sobre as demais variáveis não se observam efeitos significativos das variáveis independentes, todavia é importante registrar que a concentração tende a interferir na umidade e higroscopicidade dos pós provocando respectivamente o aumento e diminuição das mesmas. Já o aumento da temperatura tende a diminuir a solubilidade e higroscopicidade dos pós. Estes resultados mostram preliminarmente a importância de se ampliar o delineamento experimental de forma a se obter uma avaliação estatística que conduza à otimização do processo.

\section{CONCLUSÃO}

Este trabalho teve como objetivo principal avaliar a influência da temperatura e da concentração de adjuvante no rendimento e nas características físico-químicas do pó do extrato da casca de jampo obtido mediante secagem em spray dryer. Frente aos resultados encontrados, conclui-se que o pó produzido apresenta boas condições de armazenamento e conservação. Tal fato é justificado pelo baixo teor de umidade associado a uma baixa atividade de água. Em relação às análises estatísticas, verifica-se que a temperatura e a interação entre as variáveis de operação temperatura e concentração influenciam significativamente no rendimento. Trabalhos posteriores a este apontam para a análise do tempo de prateleira do produto e análises térmicas, a fim de indicar que tipo de característica é predominante na estrutura do pó e a que fim se destina: se para uso como aditivo em alimentos ou em sistemas de liberação controlada.

\section{NOMENCLATURA}

aW - Atividade de água;

$\mathrm{C}(\%)$ - Concentração de goma arábica em porcentagem;

$\mathrm{H}(\%)$ - Higroscopicidade do pó em porcentagem;

$\mathrm{R}(\%)$ - Rendimento do processo em porcentagem;

$\mathrm{S}(\%)$ - Solubilidade do pó em porcentagem;

$\mathrm{T}\left({ }^{\circ} \mathrm{C}\right)$ - Temperatura de secagem em graus Celsius; 
$\mathrm{X}(\%)$ - Umidade do pó em porcentagem.

\section{REFERÊNCIAS}

BARBOSA, S. J. Qualidade de suco em pó de mistura de frutas obtido por spray drying. 2010. 122 f. Dissertação (Mestrado) - Curso de Produção Vegetal no Semiárido, Universidade Estadual de Montes Claros, Janaúba, 2010.

BOBBIO, F. O. et al. Identificação e quantificação das antocianinas do fruto do açaizeiro (Euterpe oleracea) Mart. Ciência e Tecnologia de Alimentos, [s.l.], v. 20, n. 3, p.388-390, dez. 2000.

CANO-CHAUCA, M.; STRINGHETA, P. C.; RAMOS, A. M.; CAL-VIDAL, C. Effect of the carriers on the microstructure of mango powder obtained by spray drying and its functional characterization. Innovative Food Science and Emerging Technologies, Amsterdam, v.6, p.420-428, 2005

EASTMAN, J. E.; MOORE, C. O. Cold water soluble granular starch for gelled food composition. U. S. Patent 4465702, 1984.

KONCZAK, I.; ZHANG, W. Anthocyanins - More Than Nature's Colours. Journal of Biomedicine and Biotechnology, v. 5, n. x, p. 239-240, 2004.

LANCHA, J. P. et al. Desidratação de Polpa de Pitanga e Jabuticaba em Spray Dryer: Condições de Processo e Propriedades Físico-químicas do Pó. In: Congresso Interinstitucional de Iniciação Científica, 6., 2012, Jaguariúna. [S.l.: s.n.], 2012. 10 p. Disponível em: <http://webmail.cnpma.embrapa.br/eventos/2012/ciic/cd_anais/Artigos/re12227.pdf>. Acesso em: 20 mar. 2017.

LULE, S. U.; XIA, W. Food phenolics, pros and cons: A review. Food Review International, v. 21, n. 4, p. 367-388, 2005.

MOREIRA, G. É. G. et al. Physical properties of spray dried acerola pomace extract as affected by temperature and drying aids. Lwt - Food Science And Technology, [s.1.], v. 42, n. 2, p.641-645, mar. 2009. Elsevier BV. http://dx.doi.org/10.1016/j.1wt.2008.07.008

MOURA NETO, L. G. de. Pó de cajá (Spondia mombin l.) atomizado: caracterização físicas, físico-químicas, sensoriais e avaliação do comportamento higroscópico. 2011. 98 f. Dissertação (Mestrado) - Curso de Ciência e Tecnologia de Alimentos, Universidade Federal do Ceará, Fortaleza, 2011.

TONON, R. V.; BRABET, C; HUBINGER, M. D. Aplicação da secagem por atomização para a obtenção de produtos funcionais com alto valor agregado a partir do açaí. Inclusão Social, Brasília, v. 6, n. 2, p.70-76, jan. 2013. 